\title{
Determination of burr thickness in high-speed cutting of pipe bundles with circular saws
}

\author{
Olga A. Makarova, Alexey A. Zhdanov, Alla A. Kozhevnikova, Ruslan I. Arzhukhanov*, \\ and $V u$ Van Giang
}

Volgograd State Technical University, 400005, Volgograd, Lenin avenue, 28, Russia

\begin{abstract}
The method of high-speed cutting of cold rolled steel with circular saws is one of the most common in modern mechanical engineering. But often, cutting cold rolled metal is accompanied by the formation of a burr at the ends of the blanks. This machining method is characterized by high productivity, significant tool wear and intense heating of the workpiece due to high cutting speeds. The thickness of this burr is directly dependent on the pipe material, the temperature in the cutting zone and the saw feed. The article proposes a mathematical relation to determine the thickness of the burr by these parameters.
\end{abstract}

An experimental study was carried out at Volzhsky Pipe Plant, JSC using modern technological equipment in an automated production environment [1].

The pipe cutting process is carried out at the stack cutting unit of the TPTs - 2 pipe rolling plant of VPP JSC. A circular saw for stack cutting has the following geometrical characteristics: diameter $-2000 \mathrm{~mm}$; tooth height $-10.3 \mathrm{~mm}$; cutting disc thickness $-8 \mathrm{~mm}$; 400 teeth; the size of the back platform - up to $3.5 \mathrm{~mm}$; profile angle - $40^{\circ}$; made of steel 50HGFA.

As an object of research, pipes made of stainless steels $08 \mathrm{X} 13,12 \mathrm{X} 13,20 \mathrm{X} 13$ were used, the physical properties of which are presented in Table 1.

Table 1. Physical properties of steels 08X13, 12X13, 20X13

\begin{tabular}{|c|c|c|c|}
\hline Grade & $\begin{array}{c}\text { Ultimate tensile } \\
\text { strength } 20^{\circ} \mathrm{C} \sigma_{t}, \\
\mathrm{MPa}\end{array}$ & $\begin{array}{c}\text { Material thermal diffusivity } \\
\omega_{\text {pipe }}, \mathrm{m} 2 / \mathrm{s}\end{array}$ & $\begin{array}{c}\text { Carbon loads in } \\
\text { steel } C, \%\end{array}$ \\
\hline $08 \mathrm{X} 13$ & 480 & $7.8 \cdot 10^{-6}$ & 0.08 \\
\hline $12 \mathrm{X} 13$ & 410 & $6.5 \cdot 10^{-6}$ & 0.12 \\
\hline $20 \mathrm{X} 13$ & 710 & $6.1 \cdot 10^{-6}$ & 0.20 \\
\hline
\end{tabular}

Cutting a bundle of stock with a circular saw rotating at a high peripheral speed (100$110 \mathrm{~m} / \mathrm{s})$ and with low feeds $(0.008 \mathrm{~m} / \mathrm{s}-0.028 \mathrm{~m} / \mathrm{s})$ leads to significant heating of the processed material in the near-contact zone. This volume of material is squeezed out by the front surface of the saw tooth from the deformation zone with the formation of a burr at the

\footnotetext{
* Corresponding author: kinnomans@mail.ru
} 
end of the pipe. To calculate the size of the burr, it is necessary to determine the size of the temperature field arising from the heating of the contact zone by the saw.

To solve the problem of thermal conductivity in the machined material, the method of heat sources is used [2,3]. The contact zone directly under the saw can be represented as a body on which a strip-like heat source moving at a speed $S$ acts.

Reflection of the heat flux from the interface when the tool approaches the pipe edge increases the temperature of the machined material. The temperature at a distance $y$ from the heat source is:

$$
T(y)=3100 \cdot \exp \left(-\frac{S \cdot y}{2 \omega_{\text {pipe }}}\right) .
$$

where $S$ - saw feed speed per second, $\mathrm{m} / \mathrm{s}$;

$\omega_{\text {pipe }}$ - coefficient of thermal diffusivity of the pipe material, $\mathrm{m} 2 / \mathrm{s}$.

Burr formation and rupture depends on the stresses in the material at a distance $y$ from the contact zone. The time limit of resistance ot (T) decreases with an increase in the heating temperature of the material (Figure 1).

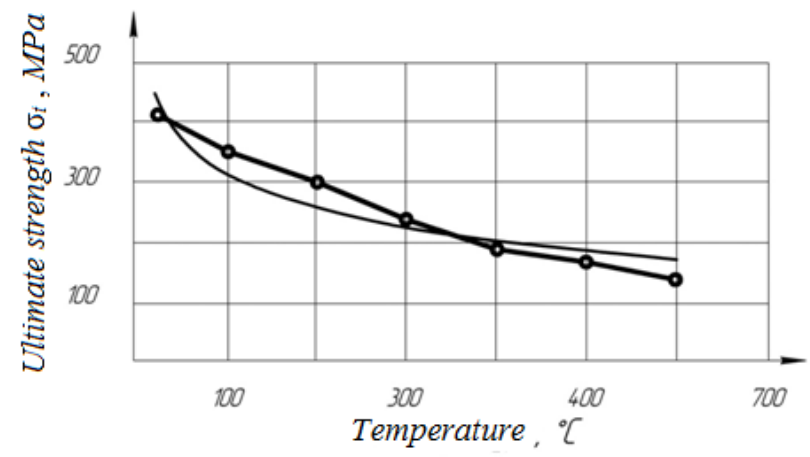

Fig. 1. Change in the strength of the pipe material 12X13 depending on temperature.

To determine the mathematical dependence of voltage on temperature, an approximation using a logarithmic function is done:

$$
\sigma(y)=k_{1} \cdot \ln (T)+k_{2}=k_{1} \cdot\left(-\frac{S \cdot y}{2 \omega_{\text {pipe }}}\right)+k_{2}+8,039 \cdot k_{1}
$$

where $k_{1}, k_{2}$ - coefficients of logarithmic approximation.

An approximation of the dependence of the ultimate strength on temperature for various steels is given in Table 2 .

Table 2. Parameters of the logarithmic approximation

\begin{tabular}{|c|c|c|}
\hline Grade & $\begin{array}{c}\text { Formula } \\
\sigma(y)=k_{1} \cdot \ln (T)+k_{2}\end{array}$ & Certainty factor $R^{2}$ \\
\hline $08 \mathrm{X} 13$ & $\sigma(y)=-38 \cdot \ln (T)+601$ & 0.886 \\
\hline $12 \mathrm{X} 13$ & $\sigma(y)=-80 \cdot \ln (T)+682$ & 0.906 \\
\hline $20 \mathrm{X} 13$ & $\sigma(y)=-74 \cdot \ln (T)+947$ & 0.905 \\
\hline
\end{tabular}

The stresses arising from the cutting forces in the heated pipe material cause the metal to stretch and form a burr at the end (Figure 2). When the stresses reach the ultimate 
strength $\sigma_{t}(\mathrm{~T})$, the burr is separated from one end of the pipe. The burr remains at the end of another pipe, causing a loss in cut quality.

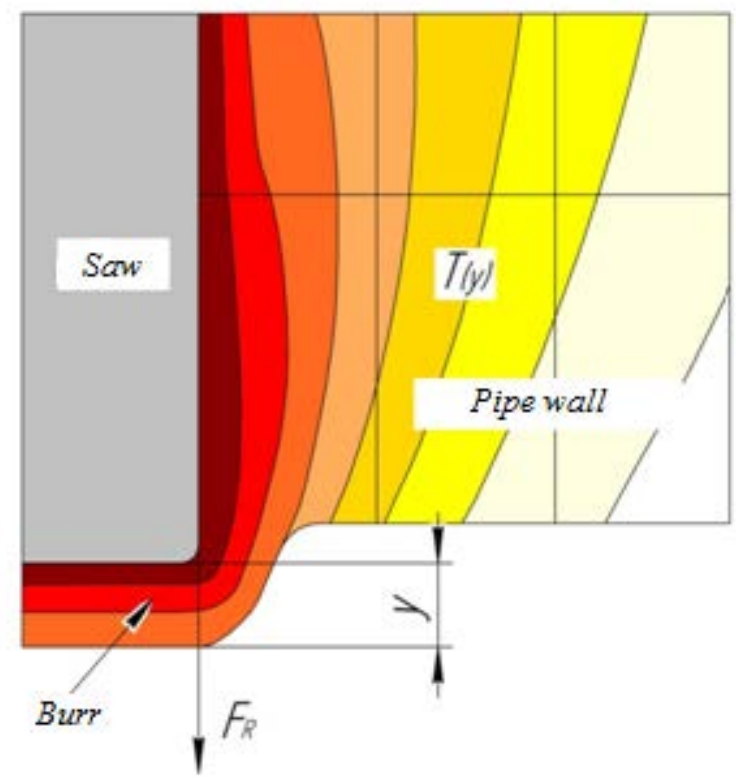

Fig. 2. Burr rupture under the action of the projection of the tensile normal cutting force

Tensile stresses arising from cutting forces in the near-contact zone at a distance $y$ can be calculated by the formula:

$$
\sigma(y)=\frac{F_{R}}{2 l \cdot y^{\prime}}
$$

where $F_{R}$ - radial (normal) cutting force, $\mathrm{H}$;

$l$ - half the length of the deformable perimeter of the burr, $\mathrm{m}$;

$y$ - deformable burr thickness, $\mathrm{m}$.

Using the given expressions, we define the radial cutting force $\mathrm{F}_{R}$ acting on the zone of contact with the pipe, $\mathrm{H}$ :

$$
F_{R}=\frac{3.14 \cdot 10^{9} \cdot l \cdot B_{c w} \cdot S \cdot \cos \varpi \cdot\left(\frac{l_{b}}{l_{z}}\right)^{0.67} \cdot\left(\frac{\sigma_{t}}{440}\right)^{0.304}}{(0.114-0.08 \cdot C) \cdot \sqrt{v}}
$$

where $S$ - longitudinal feed of the saw blade, $\mathrm{m} / \mathrm{s}$;

$\varpi$ - angle of action of the radial cutting force $\mathrm{F}_{R}$ (normal to the arc of contact between the saw and workpieces);

$v$ - circular saw speed, $\mathrm{m} / \mathrm{s}$;

$l_{b}$ - length of the contact pad along the back edge of the saw tooth, $\mathrm{mm}$;

$z_{\kappa}$ - distance between saw teeth, mm;

$B_{c w}-$ cut width $\left(B_{c w}=B+0.002\right), \mathrm{m}$;

$B$ - saw width, mm;

$C$ - carbon loads in cut steel, $\%$;

$\sigma_{t}-$ tensile strength of the cut material at $20^{\circ} \mathrm{C}, \mathrm{MPa}$.

Transforming expression (2), and taking into account dependence (3), we find tensile stresses in the near-contact zone according to the formula, MPa: 


$$
\begin{gathered}
\sigma(y)=\frac{5.35 \cdot 10^{3} \cdot B_{c w} \cdot S \cdot \cos \varpi \cdot\left(\frac{l_{b}}{l_{z}}\right)^{0.67} \cdot\left(\frac{\sigma_{t}}{440}\right)^{0.304}}{(0.114-0.08 \cdot C) \cdot y \cdot \sqrt{v}}= \\
=\frac{5.35 \cdot 10^{3} \cdot 0.01 \cdot S \cdot 0.5 \cdot\left(\frac{3.5}{15.7}\right)^{0.67} \cdot\left(\frac{\sigma_{t}}{440}\right)^{0.304}}{(0.114-0.08 \cdot C) \cdot y \cdot \sqrt{105}}=\frac{0.15 \cdot S \cdot \sigma_{t}{ }^{0.304}}{(0.114-0.08 \cdot C) \cdot y}
\end{gathered}
$$

Equating the stresses, determined by the heating temperature (2), in the machined material, and the stresses determined by the radial cutting force (4), we obtain a quadratic dependence:

$$
\begin{gathered}
k_{1} \cdot\left(-\frac{S \cdot y}{2 \omega_{\text {pipe }}}\right)+k_{2}+8.039 \cdot k_{1}=\frac{0.15 \cdot S \cdot \sigma_{t}^{0.304}}{(0.114-0.08 \cdot C) \cdot y} \\
k_{1} \cdot\left(-\frac{S \cdot y^{2}}{2 \omega_{\text {pipe }}}\right)+\left(k_{2}+8.039 \cdot k_{1}\right) \cdot y-\frac{0.15 \cdot S \cdot \sigma_{t}^{0.304}}{(0.114-0.08 \cdot C)}=0
\end{gathered}
$$

The solution to this quadratic equation is an expression that determines the thickness of the burr for various conditions:

$$
\begin{aligned}
y=\frac{(-1) \cdot \omega_{\text {pipe }}}{k_{1} \cdot S} & \\
& \cdot\left(\sqrt{\left(k_{2}+8.039 \cdot k_{1}\right)^{2}-\frac{0.3 \cdot k_{1} \cdot S^{2} \cdot \sigma_{t}^{0.304}}{(0.114-0.08 \cdot C) \cdot \omega_{\text {pipe }}}}\right. \\
& \left.-\left(k_{2}+8.039 \cdot k_{1}\right)\right)
\end{aligned}
$$

The calculation of the burr thickness for stainless steels shows sufficient accuracy. This is confirmed by experimental data (Figure 3).

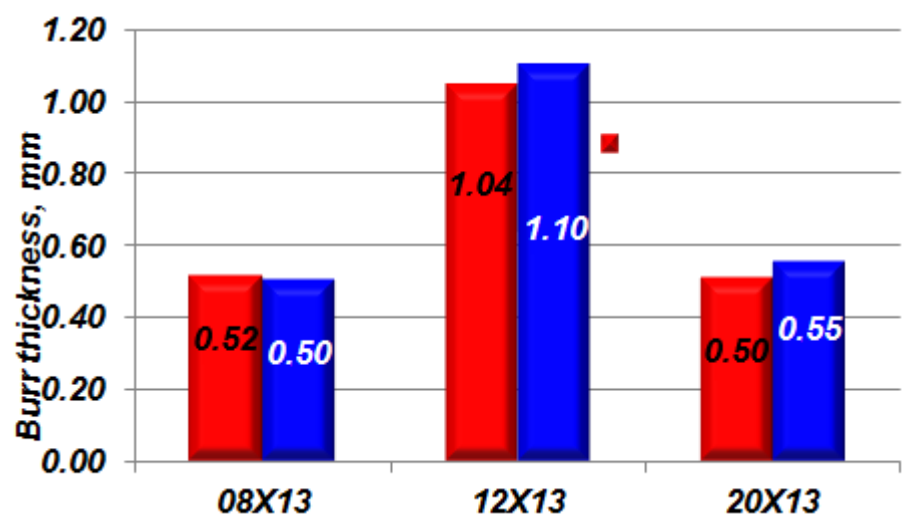

Fig. 3. Change in burr thickness depending on the pipe material.

\section{Conclusion}

Analyzing the process of high-speed cutting, we can conclude that the thickness of the burr is influenced by temperature, feed, chemical composition and strength of the workpiece 
material. The conducted studies have shown that it is rather difficult to predict the burr thickness based on the properties of the material being machined; therefore the obtained method for calculating the burr is of particular interest for modern mechanical engineering.

\section{References}

1. Yu.N. Polyanchikov, A.I. Bannikov, A.I. Kurcheniko, O.A. Makarova, Investigation of the size of the burr during thermal friction cutting (Issledovanie razmerov zausentsa pri termofriktsionnom rezanii), Izvestiya VolgGTU, Progressive technologies in mechanical engineering (Progressivnye tekhnologii v mashinostroenii), 4(9), pp. 33-35 (2008)

2. 2. A.V. Konovalov et al., Theory of welding processes (Teoriya svarochnyh processov), M.: Izd-vo MGTU i. NE Baumana, p. 279 (2007).

3. 3. A.N. Reznikov, Thermal physics of materials machining processes (Teplofizika protsessov mekhanicheskoy obrabotki materialov), M.: Mashinostroyeniye, Theory of welding processes (Teoriya svarochnyh processov), M.: Izd-vo MGTU i. NE Baumana, p. 279 (1981) 